\title{
Constant pressure control for variable-rate spray using closed-loop proportion integration differentiation regulation
}

\author{
Wei Deng, Chunjiang Zhao, Liping Chen, Xiu Wang \\ Beijing Research Center of Intelligent Equipment for Agriculture; National Research Center of \\ Intelligent Equipment for Agriculture; Key Laboratory of Agri-informatics, Ministry of Agriculture; \\ Beijing Key Laboratory of Intelligent Equipment Technology for Agriculture, Beijing, China
}

\begin{abstract}
Traditional sprayers adopt large-area uniform pesticide application, resulting in a low effective utilisation of pesticide and a harmful effect to the natural environment. Variable-rate spray is the key point to precision chemical application. However, it is inevitable that the spray pressure sharply fluctuates during variable-rate spray, which will definitely influence the spray characteristics, such as spray droplet sizes, spray angles, spray droplet velocities, etc., and reduce the efficiency of pesticide applications. Therefore, the research on how to keep the spray pressure constant during the process of variable-rate spray has practical significance to precision pesticide applications. In order to achieve the stability of spray pressure for variable-rate spray, a sprayer with constant-pressure control was set up using a closed-loop proportion integration differentiation (PID) controller of constant-pressure water-supply, which employed the techniques of single-phase alternating current (AC) chopper variablevoltage control and PID feedback regulation. Using hollow-cone nozzles, the spray volume was changed by adjusting spray pressure, fre-
\end{abstract}

Correspondence: Wei Deng, Beijing Research Center of Intelligent Equipment for Agriculture, Shuang Hua Yuan Middle Road No. 11, Haidian District, Beijing 100097, China. E-mail: dengw@nercita.org.cn

Key words: Variable rate application; spraying; pressure, stability; agricultural chemical.

Acknowledgements: this research was financially supported by the National Key Research and Development Plan of China (No. 2016YFD0700104) and the National High Technology Research and Development Program of China (984 Program) (2011-G32). The authors acknowledge the National Experimental Station of Precision Agriculture of China.

Conflict of interest: the authors declare no potential conflict of interest.

Received for publication: 23 September 2015.

Accepted for publication: 20 April 2016.

(C) Copyright W. Deng et al., 2016

Licensee PAGEPress, Italy

Journal of Agricultural Engineering 2016; XLVII:512

doi:10.4081/jae.2016.512

This article is distributed under the terms of the Creative Commons Attribution Noncommercial License (by-nc 4.0) which permits any noncommercial use, distribution, and reproduction in any medium, provided the original author(s) and source are credited. quency, and duty cycle of electromagnetic valve switching. The spray features concerning the spray angle and the spray volume distribution were studied in laboratory. The conclusions are as follows: i) for a given input spray pressure, the closed-loop controller with AC chopper and PID feedback regulation can effectively control the pressure fluctuations during the variable-rate spray through varying the frequency and the duty cycle; ii) the spray angle was slightly affected by the flow-rate change through adjusting the frequency and the duty cycle of electromagnetic valves or changing the number of open nozzles. The spray angle changes were controlled within the range of the maximum deviation $0.87^{\circ}$ from mean value and the minimum deviation $0.03^{\circ}$ from mean value; iii) when the spray pressure was set as $0.3 \mathrm{Mpa}$, the peak radial position of the spray volume distribution basically unchanged and the spray volume and the peak values of the spray distribution gradually increased with the increasing duty cycle. When the setting pressure was increased, the spray volume increased and the peak radial position of the spray distribution gradually expanded toward outside, however the peak value of the spray distribution decreased a little.

\section{Introduction}

In the spraying process of traditional pest control, uniform applications of agro-chemicals were utilised in large area, neither considering the differences of plant covers and row spacing in pesticide spraying area, nor thinking about the diverse degree of pest and disease disasters in different plots, which led to serious issues of excessive uses and low effective utilisation rate of chemical pesticides (Praice et al., 1996; Yang et al., 2002; He, 2004). Off-target deposition of pesticide will cause severe problems of environmental pollution and pesticide waste (Chen and Zheng, 2005). Precision farming machineries based on variable-rate spraying can effectively improve the utilisation rate of pesticides and reduce the environmental pollution of chemical pesticides (Escolà et al., 2013), in which the core technology is to vary the spray volume according to the different pesticide needs in different field parcels using technologies of information positioning like photoelectric detection technique (Deng et al., 2008; Zhai et al., 2012), ultrasonic detection technique (Zhang et al., 2010; Alexandre et al., 2011), laser detection technique (Joan et al., 2009; Yu et al., 2013), and image processing detection technique (Shen et al., 2013; Gui and $\mathrm{Xu}, 2014$ ) and variable-rate spray like pulse-width modulation-based (PWM-based) intermittent variablerate spray (Giles and Comino, 1990; Giles and Ben-Salem, 1992), PWM-based continuous variable-rate spray (Deng and Ding, 2008; Deng et al., 2011), injection spray (Sudduth et al., 1995), and so on.

Although it is in a situation of a given liquid pressure that vari- 
able-rate spray will cause dramatic fluctuations of spray pressure, which will alter the atomisation features and result in significant changes in spray droplet size, so that spray deposition characteristics and chemical application effect are severely influenced (Giles and Comino, 1990; Giles and Ben-Salem, 1992; Deng and Ding, 2008; Deng et al., 2008, 2011). For the sophisticated requirements of precision chemical application, the problem of the pressure stability during variable-rate spraying has been noticed in recent studies. Huang and his co-authors (Huang et al., 2011) designed a pressure-based variable-rate spray system using AT89S52 microcontroller (Atmel Corp., San Jose, CA, USA) in which the liquid pressure in pipes was controlled using proportion integration differentiation (PID) method and spray volume was regulated using fuzzy control method. Shao and his co-authors (Shao et al., 2005, 2006) divided the management area into 30 different pesticide application plots combining planting densities, diseases and pest levels and then implemented variable-rate spray using fuzzy controller according to the different demands of water and pesticide in different plots. Chen and his colleagues (Chen et al., 2011) designed a kind of adaptive neural-fuzzy controller based on different weed area and running speed of sprayers, by which the faster the sprayer runs and the larger the weed area is, the higher the need of spray volume is.

Besides these methods of pressure-based variable-rate spray, there are many other kinds of variable-rate spray techniques, such as PWMbased intermittent and PWM-based continuous variable-rate spray, with which methods drastic fluctuations of the liquid pressure always accompany the process of variable-rate spraying even in a given spray pressure. The general solution was rough open-loop regulating control by using pressure regulating valves. Therefore, in order to improve the control accuracy of spray pressure, this study attempted to stabilise the liquid pressure of PWM-based variable-rate spray at a constant spray pressure using PID close-loop control and single-phase alternating current (AC)-chopper variable-voltage technology.

In this study, a test bed of constant-pressure variable-rate spray was first set up and then the effects of stabilising voltage were tested on the conditions of the open-loop pressure control using pressureregulating valves and the close-loop pressure control using PID controller. The objective of the experimental research is to find out the effect of variable-rate spray with constant-pressure control on the spray characteristics of spray angle and the spray distribution for XVK-18-brand hollow-cone nozzles.

\section{Materials and methods}

\section{Experimental set-up}

\section{Principle of constant-pressure control for variable-rate spray}

The study realised control of constant-pressure water supply by combining AC-chopping variable-voltage speed control and PID close-loop feedback regulating and achieved variable-rate spray using PWM control method. The principle schematic of constant pressure control for variable-rate spray is shown in Figure 1. The techniques of PID closeloop regulating and of single-phase AC-chopper variable-voltage control were adopted for the constant pressure control, in which the difference value, obtained by comparing the actual pipeline pressure and the setting pressure, is input to PID calculator and then to AC-chopper to work out the control signal of chopping voltage. The chopping voltage drives the pump motor to achieve required rotating speed and realise the dynamic balance of the pipeline pressure within the close-loop control system. The variable-rate control was realised using PWM technology, in which the frequency and the duty cycle of the electromagnetic valve are adjusted to change the spray volume.

\section{Set-up}

The equipment of variable-rate spray with constant pressure control is mainly composed of a controller of constant-pressure water supply, an electric impeller pump, a $12 \mathrm{~V}$ switch electromagnetic valve, a transmissible pressure gauge, PWM controller, spray nozzles, and pipelines. The controller of constant-pressure water supply, manufactured by Laiyun Technology CO. LTD. (Dezhou, Shandong, China) and mainly consisting of a PID regulator and a single-phase AC chopper, can accomplish the comparison of working pressure and setting pressure and let the difference value input to PID regulator for proportion, integral, and differential calculations. The output signal from PID is then converted to a chopping voltage by the single-phase AC-chopper, which can be used to adjust the running speed of the motor pump and realise the control of water supply pressure. The transmissible pressure gauge can transform the signal of hydraulic pressure in pipeline into a 4-20 $\mathrm{mA}$ electrical signal, which is transmitted to PID regulator in control unit of constant-pressure water supply, so as to realise the close-loop feedback of constant pressure control for variable-rate spray. The electric impeller pump was a integrate of a pump motor and a pump and the

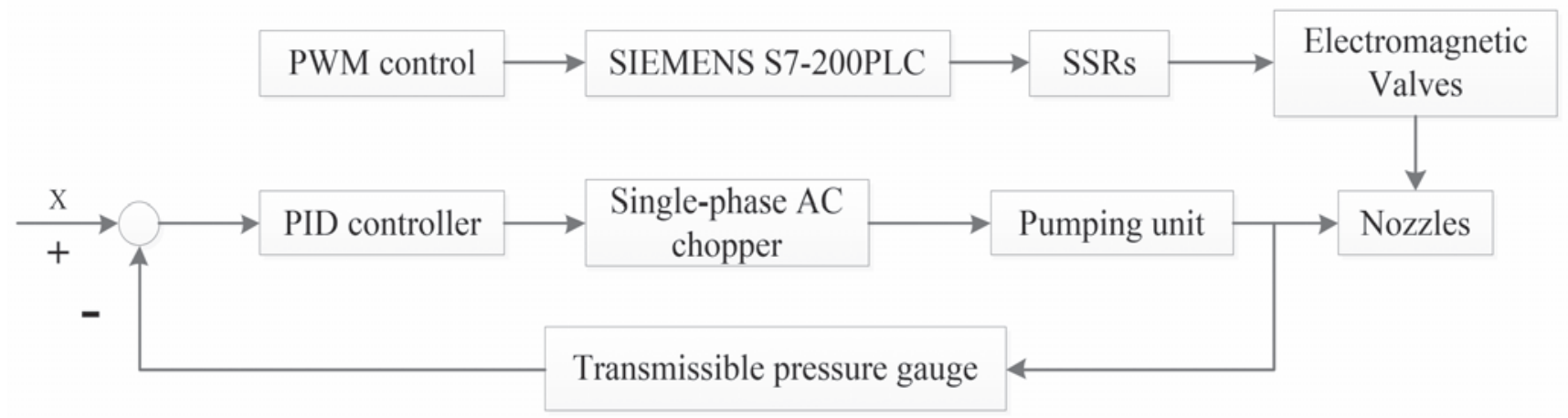

Figure 1. Schematic principle of constant pressure control for variable-rate spray. PWM, pulse-width modulation-based; SSR, solidstate relay; PID, proportion integration differentiation; AC, alternating current. 
speed of the water pump motor was adjusted using AC-chopping voltage-adjusting technology for asynchronous motor (Ma and Qi, 2006).

When the actual water pressure measured by transmissible pressure gauge is greater than the setting pressure, the AC-chopping voltageadjusting signal will make the speed of water pump motor decrease. Otherwise, the speed of pump motor will be increased when the actual water pressure is less than the setting pressure.

Voltage-regulating speed control method has the shortages of relatively small range of speed regulation and low accuracy, however its circuit is simple, the cost in practical application is much lower than that of variable-frequency speed control, and the more speed controlling performance can meet the needs of loads like dragging pumps (Ling and Deng, 2005).

\section{Proportion integration differentiation controller}

PID controller is a control loop feedback mechanism combining proportional, integral, and differential control and is commonly used in engineering control system because it is an ideal method to solve problems when the property of a controlled object or a control system is not fully known or the main parameters of a system cannot be measured using related measurement means. A PID controller continuously calculates an error value as the difference between a measured process variable and a desired setpoint. The controller attempts to minimise the error over time by adjustment of a control variable, such as the position of a control valve, a damper, or the power supplied to a heating element, to a new value determined by a weighted sum. The expression is as Eq. (1).

$$
u(t)=\mathrm{P} \cdot e(t)+\mathrm{I} \cdot \int_{0}^{t} e(\tau) d \tau+\mathrm{D} \cdot \frac{d e}{d t}
$$

where $P, I$, and $D$, all non-negative, denote the coefficients for the proportional, integral, and derivative terms, respectively. $P$ accounts for present values of the error (e.g., if the error is large and positive, the control variable will be large and negative), $I$ accounts for past values of the error (e.g., if the output is not sufficient to reduce the size of the error, the control variable will accumulate over time, causing the controller to apply a stronger action), and $D$ accounts for possible future values of the error, based on its current rate of change. By tuning the three parameters of the model, a PID controller can deal with specific process requirements and control and adjust the system error using the controlling quantity worked out by the combination of proportional, integral, and differential calculators (Hu, 2008; Yang and Yang, 2009). The response of the controller can be described in terms of its responsiveness to an error, the degree to which the system overshoots a setpoint, and the degree of any system oscillation (see the block diagram of a PID controller at WIKI website: https://en.wikipedia.org/wiki/ PID_controller).

\section{Single-phase alternating current chopper}

The principle of chopping-style AC-voltage regulating is that the continuous sinusoidal input voltage is cut into discrete voltage segments by means of repeated on-off operation within one cycle of the power supply using switching devices with much higher frequency than that of the power supply. The output voltage can be adjusted by changing the width of those discrete voltage segments or the on-off switching cycle. The quality of the output voltage from chopped-voltage regulating circuit is high and exerts little effect on power source.

The control circuit of single-phase AC-voltage chopper control is shown in Figure 2A. $s_{1}$ and $s_{2}$ are both two-way switch, whereas $s_{1}$ is the chopper switch in the main circuit, $s_{2}$ is that in the after-flow circuit, and the signals from $s_{1}$ and $s_{2}$ form complementary control on a switching sequence. Because of the complementation of the on-off state of $s_{1}$ and $s_{2}$, the output voltage $u_{0}$ can be expressed as Eq. (2) (Zhou, 2013), where $u_{0}$ is zero when $s_{1}$ is off and $s_{2}$ is on, $u_{0}$ is equal to the input voltage $u_{i}$ when $s_{1}$ is on and $s_{2}$ is off.

$$
u_{o}=\left\{\begin{array}{c}
0, s_{1}=0, s_{2}=1 \\
u_{i}, s_{1}=1, s_{2}=0
\end{array}\right.
$$

Supposing the power input is $u_{i}=u_{m} \sin \omega t \omega=2 \pi / T$, the waveform of the output voltage of chopper circuit working at a steady state is shown in Figure 2B. The formula can be expanded into Fourier series, shown as Eq. (3).

$$
\begin{aligned}
& u_{o}=u_{m} \sin \omega t\left[D+\frac{2}{-} \sum_{i=1}^{\infty} \sin \phi_{i} \cos \left(i \omega_{s} t-\phi_{i}\right) / i\right] \\
& =D u_{m} \sin \omega t+\frac{u_{m}}{\pi} \sum_{i=1}^{\infty} \frac{\sin \phi_{i}}{i}\left\{\sin \left[\left(i \omega_{s}+\omega\right) t-\phi_{i}\right]\right\}
\end{aligned}
$$

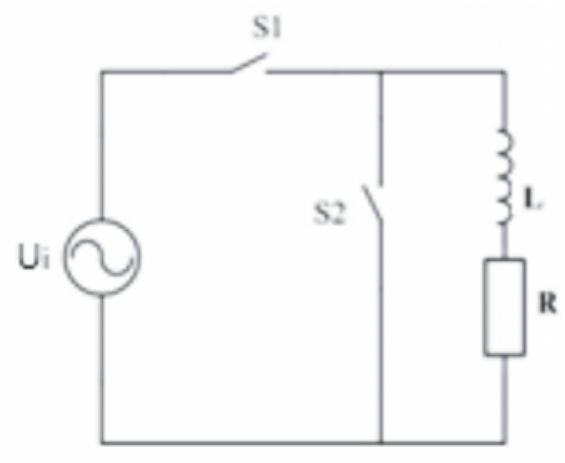

A

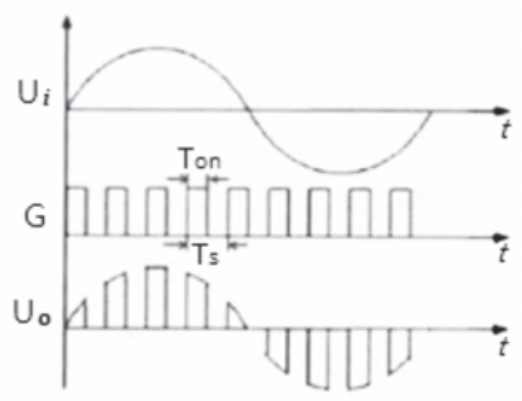

B

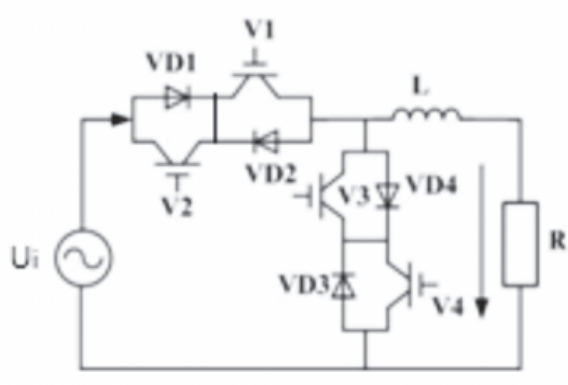

C

Figure 2. A-C) Output voltage waveform of alternating current (AC) chopper. $S_{1}$, chopper switch in the main circuit; $S_{2}$, chopper switch in the after-flow circuit; $U_{i}, U_{o}, T_{o n}, T_{s}$ and $t$, see explanation in Eq. (2); V1, V2, V3 and V4, semiconductor switch elements; VD1, VD2, VD3 and VD4, anti-parallel diodes; $G$, rectangular pulse; $L$, load impedance; $R$, load resistance. 
where:

$\omega_{s}=2 \pi / T_{s}$ is the angular frequency;

$\phi_{i}=i \pi D$ is the conduction angle;

$D=T_{o n} / T_{s}$, the ratio of the switch conduction time to the switching period is the duty cycle.

$D u_{m} \sin \omega t$ represents fundamental wave and $\omega$ is the angular frequency of fundamental wave. It can be seen from the formula that changing duty cycle $D$ can achieve the goal of regulating voltages (Kazerani, 2003).

The circuit shown in Figure 2C is the topology structure of the main circuit, where V1, V2, V3, and V4 are respectively the semiconductor switch element, named insulated gate bipolar transistor, of VD1, VD2, VD3, and VD4, which are the anti-parallel diodes.

\section{Programmable logic controller}

Programmable logic controller (PLC) was used to control solid-state relays so as to control electromagnetic valves. With constant pressure control, the variable-rate spray was realised through controlling the onoff status of six electromagnetic valves, which requires the controller having at least six output interfaces. For this reason, Model S7-200 PLC, manufactured by Siemens AG (Munich, Germany), was chosen to be the controller of variable-rate spray, whose host computer is CPU224 with 14 input interfaces and 10 output interfaces, to meet the control requirements.

\section{Solid-state relay}

A kind of solid-state relay (SSR), model SSR-D204L, was chosen in the system. The maximum operating current is $4 \mathrm{~A}$, the voltage of the input control signal is $3-10 \mathrm{~V}$ direct current (DC), and the working voltage of the output load is 5-180 V DC.

\section{Direct current boost converter}

In the outdoor experiment, the variable-rate spray with constant pressure control is powered by the battery of the agriculture tractor which can just provide $12 \mathrm{~V}$ DC power supply. However, S7-200PLC needs $24 \mathrm{~V}$ DC power supplying. Therefore, a $12 \mathrm{~V} \mathrm{DC}-24 \mathrm{~V}$ DC boost converter was used in the control circuit to supply $24 \mathrm{~V}$ DC power to S7200PLC.

\section{Pulse width modulation controller}

Pulse width modulation technology is one of the modulation methods of the electrical pulse signal. The process in which the switch cycle $T$ is unchanged and the switch turn-on time $t_{\text {on }}$ is adjusted is called pulse-width modulation, where $t_{\text {on }}$ is the turn-on time of the output voltage, $t_{\text {off }}$ is the turn-off time of the output voltage, $\phi=t_{\text {on }} T$ is the conduction duty cycle, or duty cycle for short (Wang and Huang, 2000). The switch cycle $T$ is the duration of time of one cycle in a repeating event, so $T$ is the reciprocal of the frequency, which is the number of occurrences of a repeating event per unit time.

Let $R(t)$ be the control signal with certain frequency produced by

Table 1. Test data of the closed-loop constant-pressure control (for each valve the frequency was $5 \mathrm{~Hz}$ and the duty cycle was $\mathbf{0 . 5}$ ).

\begin{tabular}{|c|c|c|c|c|c|c|c|c|c|c|c|c|}
\hline \multirow{3}{*}{\multicolumn{2}{|c|}{$\begin{array}{l}\text { Setting pressure } \\
p_{1} \text { (Mpa) }\end{array}$}} & \multicolumn{9}{|c|}{ Measured pressure (Kpa) } & \multirow[t]{3}{*}{$\begin{array}{l}\text { Average pressure } \\
\qquad p_{2} \text { (Kpa) }\end{array}$} & \multirow[t]{3}{*}{$\begin{array}{l}\text { Relative error } \\
\qquad p_{\mathrm{f}}(\%)\end{array}$} \\
\hline & & \multicolumn{3}{|c|}{ Nozzle 1} & \multicolumn{3}{|c|}{ Nozule 2} & \multicolumn{3}{|c|}{ Nozzle 3} & & \\
\hline & & 1 & 2 & 3 & 1 & 2 & 3 & 1 & 2 & 3 & & \\
\hline \multirow[t]{4}{*}{ One nozzle } & 0.1 & 95 & 104 & 101 & - & - & - & - & - & - & 100 & 0 \\
\hline & 0.2 & 202 & 198 & 211 & - & - & - & - & - & - & 204 & 2 \\
\hline & 0.3 & 312 & 300 & 307 & - & - & - & - & - & - & 306 & 2 \\
\hline & 0.4 & 385 & 379 & 390 & - & - & - & - & - & - & 385 & 3.75 \\
\hline \multirow[t]{4}{*}{ Two nozzles } & 0.1 & 97 & 99 & 102 & 95 & 95 & 97 & - & - & - & 97.5 & 2.5 \\
\hline & 0.2 & 197 & 206 & 213 & 206 & 200 & 191 & - & - & - & 202 & 1 \\
\hline & 0.3 & 308 & 319 & 305 & 310 & 299 & 302 & - & - & - & 307.5 & 2.5 \\
\hline & 0.4 & 368 & 375 & 366 & 372 & 375 & 384 & - & - & - & 373.5 & 6.625 \\
\hline \multirow[t]{4}{*}{ Three nozzles } & 0.1 & 96 & 99 & 102 & 97 & 96 & 100 & 92 & 93 & 97 & 97 & 3 \\
\hline & 0.2 & 202 & 202 & 212 & 191 & 201 & 206 & 206 & 215 & 196 & 203.4 & 1.7 \\
\hline & 0.3 & 302 & 306 & 304 & 310 & 309 & 302 & 317 & 308 & 312 & 307.7 & 2.6 \\
\hline & 0.4 & 375 & 374 & 374 & 365 & 356 & 367 & 362 & 360 & 366 & 366.6 & 8.36 \\
\hline
\end{tabular}

Table 2 The test data of the open-loop constant-pressure control (for each valve the frequency was $5 \mathrm{~Hz}$ and the duty cycle was $\mathbf{0 . 5}$ ).

\begin{tabular}{|c|c|c|c|c|c|c|c|c|c|c|c|c|}
\hline \multirow{3}{*}{\multicolumn{2}{|c|}{$\begin{array}{l}\text { Setting pressure } \\
p_{1} \text { (Mpa) }\end{array}$}} & \multicolumn{9}{|c|}{ Measured pressure (Kpa) } & \multirow{3}{*}{$\begin{array}{l}\text { Average pressure } \\
\qquad p_{2}(\mathrm{Kpa})\end{array}$} & \multirow{3}{*}{$\begin{array}{c}\text { Relative error } \\
p_{\mathrm{f}}(\%)\end{array}$} \\
\hline & & \multicolumn{3}{|c|}{ Nozzale 1} & \multicolumn{3}{|c|}{ Nozule 2} & \multicolumn{3}{|c|}{ Nozzle 3} & & \\
\hline & & 1 & 2 & 3 & 1 & 2 & 3 & 1 & 2 & 3 & & \\
\hline \multirow{4}{*}{ One nozzle } & 0.1 & 140 & 142 & 139 & - & - & - & - & - & - & 140 & 40 \\
\hline & 0.2 & 230 & 224 & 228 & - & - & - & - & - & - & 227 & 13.5 \\
\hline & 0.3 & 334 & 336 & 326 & - & - & - & - & - & - & 326 & 12 \\
\hline & 0.4 & 370 & 375 & 377 & - & - & - & - & - & - & 374 & 6.5 \\
\hline \multirow[t]{4}{*}{ Two nozzles } & 0.1 & 151 & 139 & 137 & 144 & 136 & 140 & - & - & - & 141 & 41 \\
\hline & 0.2 & 240 & 235 & 239 & 241 & 237 & 240 & - & - & - & 238.5 & 19.25 \\
\hline & 0.3 & 332 & 322 & 330 & 326 & 324 & 345 & - & - & - & 330 & 10 \\
\hline & 0.4 & 379 & 380 & 370 & 376 & 379 & 372 & - & - & - & 376 & 6 \\
\hline \multirow[t]{4}{*}{ Three nozzles } & 0.1 & 137 & 139 & 137 & 137 & 150 & 122 & 140 & 141 & 125 & 136.4 & 36.4 \\
\hline & 0.2 & 222 & 244 & 237 & 222 & 240 & 233 & 215 & 242 & 235 & 232.2 & 16.1 \\
\hline & 0.3 & 321 & 325 & 337 & 325 & 328 & 324 & 330 & 310 & 328 & 325.3 & 8.43 \\
\hline & 0.4 & 372 & 367 & 366 & 375 & 358 & 353 & 385 & 369 & 362 & 367.4 & 8.15 \\
\hline
\end{tabular}


microcomputer and $Z(t)$ the modulated signal. If $R(t)<Z(t)$, then control circuit outputs high level and valve is open. Otherwise, if $R(t)>Z(t)$, circuit outputs low level and valve is close. Within one cycle $T$, with the valve open, flow-rate is in $t_{\text {on }}$ period; with the valve closed, no flow through the valve in $t_{\text {off }}$ period. The flow-rate can be adjusted through adjusting the duty cycle and frequency (Deng et al., 2011).

Therefore, one kind of principle of the PWM-based variable-rate spray is that the flow-rate can be adjusted by controlling the on-off states of switch electromagnetic valve using a control signal with adjustable duty cycle and frequency. The PWM controller used in this study was set up, with which operators can enter and set the frequency and duty cycle on a touch screen in order to individually control each electromagnetic valve.

\section{Test setup of constant pressure control for variable-rate spray}

The test setup of constant pressure control for variable-rate spray consists of a controller of constant-pressure water supply, a transmissible pressure gauge, an electric impeller pump, water tanks, PWM controller, a $12 \mathrm{~V}$ on-off electromagnetic valve, pressure-regulating valves, ball valves, digital pressure gauge, spray nozzles, a patternator. The water pump is a Stainless-steel self-priming electric booster pump (Zhejiang Sanwei Pump Co., Zhejiang, China), with the power supply of $220 \mathrm{~V}$ single-phase voltage and $750 \mathrm{~W}$ power, maximum pumping height of $50 \mathrm{~m}$, and maximum flow-rate $5 \mathrm{t} / \mathrm{h}$. The electromagnetic valve is a normally-closed switching electromagnetic valve, Model V2A102-03 (SMC Corp., Tokyo, Japan), with working pressure of 0 1 Mpa. Pressure-regulating valves are piston-type pressure regulator, Model Y12X (Nanjing Fangwei Valve Co., Nanjing, China), with pressure regulating range $0.1 \sim 0.8 \mathrm{Mpa}$ and highest pressure-bearing capacity 1.6 Mpa. The transmissible pressure gauge is Model TG2202 (Guangdong boanmycin Equipment Technology Co. Ltd., Zhongshan, China), with digital display, measurement range $0 \sim 0.8 \mathrm{Mpa}$, and measurement accuracy $0.001 \mathrm{Mpa}$. Spray nozzles are all selected as hollowcone nozzle, Model TXVK-18 (TeeJet Technologies, Glendale Heights, IL, USA), with the maximum working pressure of $2.0 \mathrm{Mpa}$ and the spray flow-rate of $1.18 \mathrm{~L} / \mathrm{min}$ at the pressure of $0.3 \mathrm{Mpa}$. The patternator, a square checked potted-tray with 15 horizontal squares and 15 vertical squares, was used to measure spray volume distribution and placed 50 $\mathrm{cm}$ below the nozzles. For each square the length is $50 \mathrm{~mm}$, width 50 $\mathrm{mm}$, and height $40 \mathrm{~mm}$.

\section{Experimental methods}

In order to testify the pressure stability of the variable-rate spray system with the constant-pressure control unit which was set up in the study, three tests, namely tests on constant-pressure control, spray angle, and spray distribution, were implemented on the established setup of the variable-rate spray system with a constant pressure control. For constant-pressure control test, the stability of spray pressure was compared between closed-loop control of constant-pressure controller and open-loop control with pressure-regulating valves. The more, the spray angle and the spray distribution were tested under different given spray pressure, frequency and duty cycle of control signals so as to analyse the effect of variable-rate spray with constant-pressure control on the spray angle and the spray distribution.

\section{Constant-pressure control test}

In order to vary the flow-rate, at the condition of closed-loop control, set the controller at working conditions respectively at $0.1,0.2,0.3$, and $0.4 \mathrm{Mpa}$. And at each working condition, separately let one, two, and three electromagnetic valves open. For each valve the frequency was 5 $\mathrm{Hz}$ and the duty cycle was 0.5 . Therefore, it results in 12 conditions with different flow-rates, at each of which the spray pressure was measured. At the condition of open-loop control, the spray pressure at each working conditions was measured using the same method introduced above. The working conditions designed for constant-pressure control test are shown in Tables 1 and 2.

The relative error of spray pressure $\left(p_{f}\right)$ can be worked out using the computational formula shown in Eq. (4), in which $p_{1}$ is the set pressure value (namely, mean value) and $p_{2}$ is the measurement of spray pressure. Each pressure was measured at the pump output.

$$
p_{f}=\frac{p_{2}-p_{1}}{p_{1}} \times 100 \%
$$

\section{Measurement of spray angle}

The test was performed under the condition of PID closed-loop pressure-control, in which the given pressure was respectively 0.2 and 0.3 Mpa. Setting the electromagnetic valves working at three states, namely, state 1 was that the on-off frequency was $6 \mathrm{~Hz}$ and duty cycle was 0.6 , state 2 was that the on-off frequency was $6 \mathrm{~Hz}$ and duty cycle was 0.9 , and state 3 was that the on-off frequency was $9 \mathrm{~Hz}$ and the duty cycle was 0.9. Different combinations of nozzle on-off states were just one valve open, two valves open, and three valves open. Under each working condition, the photographs of the spray angle of No.1 nozzle were quickly taken thrice using a digital camera. Then the three images were separately imported into CAD software and the angle between two obviously straight-line portions of spray image boundaries was measured. The spray angle for each working condition was obtained by averaging the three measurements. The experimental treatments for measuring spray angle are shown in Table 3.

\section{Measurement of spray distribution}

Since the frequency of PWM control signal has little influence on spray distribution of hollow-cone nozzles (Wei et al., 2013), the frequency of the control signal was not changed. In one experiment, the working conditions were set as the spray pressure at $0.3 \mathrm{Mpa}$ and the frequency at $6 \mathrm{~Hz}$, while the duty cycle is respectively $0.3,0.6$, and 0.9 . The centre of the patternator was just below the nozzle and the spray volume on the horizontal and vertical measuring points were measured

Table 3. The measured data of spray angle.

\begin{tabular}{|c|c|c|c|c|c|c|c|c|c|}
\hline $\begin{array}{l}\text { Working } \\
\text { conditions }\end{array}$ & $\begin{array}{l}\text { Setting } \\
\text { pressure } \\
\text { (Mpa) }\end{array}$ & $\begin{array}{c}\text { Frequency } \\
(\mathrm{Hz})\end{array}$ & $\begin{array}{l}\text { Duty } \\
\text { cycle }\end{array}$ & $\begin{array}{l}\text { The } \\
\text { One nozzle } \\
\text { opened }\end{array}$ & $\begin{array}{c}\text { oray angle of } \\
\text { Two nozzles } \\
\text { opened }\end{array}$ & $\begin{array}{l}\text { nozzle } \\
\text { Three nozzles } \\
\text { opened }\end{array}$ & $\begin{array}{l}\text { Mean } \\
\text { values }\end{array}$ & $\begin{array}{l}\text { Maximum } \\
\text { deviation } \\
\text { from mean }\end{array}$ & $\begin{array}{l}\text { Minimum } \\
\text { deviation } \\
\text { from mean }\end{array}$ \\
\hline $\begin{array}{l}1 \\
2 \\
3\end{array}$ & 0.2 & $\begin{array}{l}6 \\
6 \\
9\end{array}$ & $\begin{array}{l}0.6 \\
0.9 \\
0.9\end{array}$ & $\begin{array}{l}91.70 \\
91.87 \\
91.59\end{array}$ & $\begin{array}{l}91.73 \\
90.73 \\
91.37\end{array}$ & $\begin{array}{l}91.03 \\
90.62 \\
91.11\end{array}$ & 91 & 0.87 & 0.03 \\
\hline $\begin{array}{l}1 \\
2 \\
3\end{array}$ & 0.3 & $\begin{array}{l}6 \\
6 \\
9\end{array}$ & $\begin{array}{l}0.6 \\
0.9 \\
0.9\end{array}$ & $\begin{array}{l}97.51 \\
97.74 \\
97.81\end{array}$ & $\begin{array}{l}98.14 \\
98.38 \\
97.66\end{array}$ & $\begin{array}{l}97.53 \\
98.16 \\
97.51\end{array}$ & 98 & -0.49 & 0.14 \\
\hline
\end{tabular}


using measuring cylinders, which were arranged as a 2-dimentional array. In another experiment, the working conditions were set as the frequency at $6 \mathrm{~Hz}$ and the duty cycle at 0.6 , while the spray pressure was respectively $0.1,0.2$, and $0.3 \mathrm{Mpa}$. The working conditions are shown in Table 4. Rhodamine tracer was used to measure spray droplet deposition and distribution during the tests.

\section{Results and discussion}

\section{Test results of constant pressure control}

The measured data of closed-loop and open-loop spray pressure control are respectively shown in Tables 1 and 2 . The calculated relative error data of spray pressure $\left(p_{f}\right)$ were respectively imported into Excel and the responding broken line graphs are shown in Figure 3. It can be seen that the error fluctuation of closed-loop pressure control is little, while that of open-loop pressure control is relatively big. The fluctuations of pressure errors $\left(p_{f}\right)$ between the pressure points of 0.2 and 0.3 Mpa in Figure 3 are all very little. Therefore, all the setting pressures between 0.2 and $0.3 \mathrm{Mpa}$ can be regarded as stable working pressures because of the function of constant pressure controller.

The causes of the test results should be that the open-loop pressure control has the disadvantage of human operation error, which is produced by manually adjusting the pressure regulating valves and cannot be automatically repairable. While, the closed-loop pressure control can overcome this drawback and maintain the actual working pressure at a dynamic equilibrium around the setting pressure. Therefore, the pressure error was substantially unaffected by the number of on-off electromagnetic valves which were used in the spray system. Namely, when the number of the open nozzles was changed, each pressure error remained substantially unchanged. The main reason of the relatively large pressure error at $0.4 \mathrm{Mpa}$ is the limitation of the rated maximum lift of the water pump.
A) One nozzle

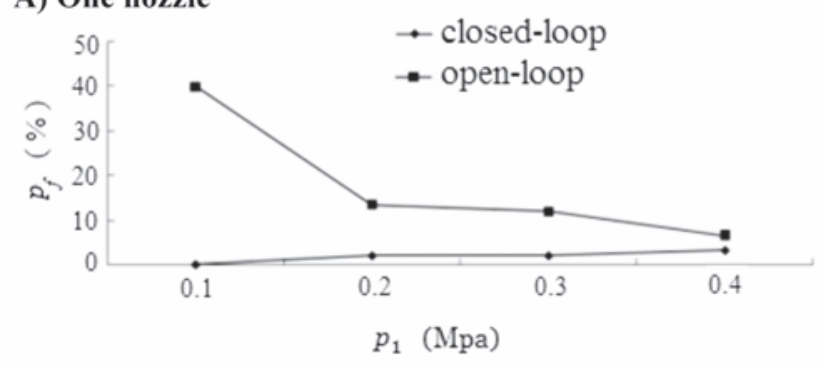

B) Two nozzles

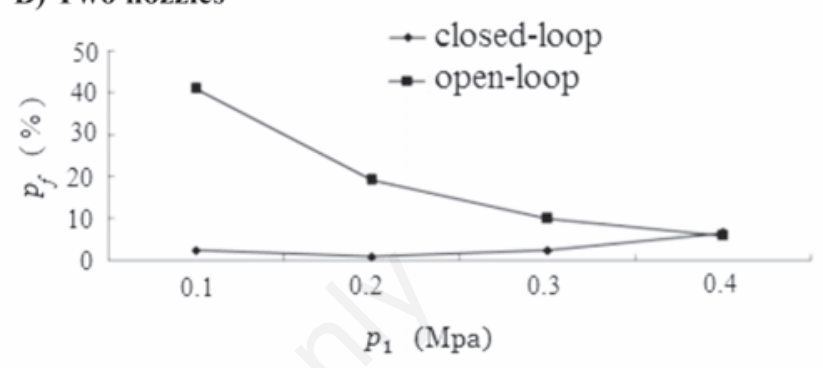

C) Three nozzles

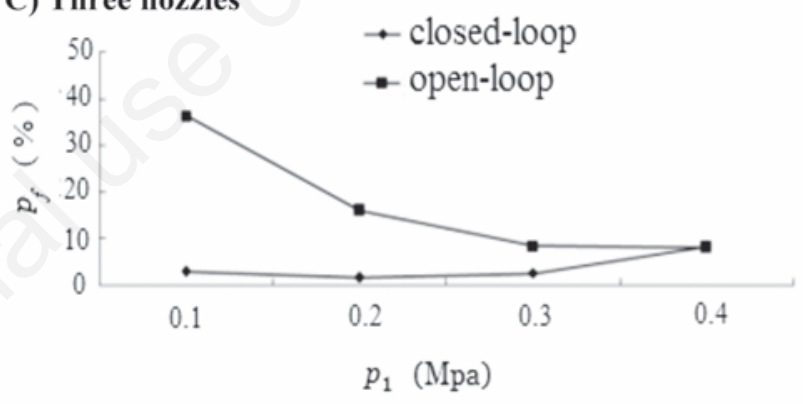

Figure 3. A-C) Test results of the constant-pressure controls.

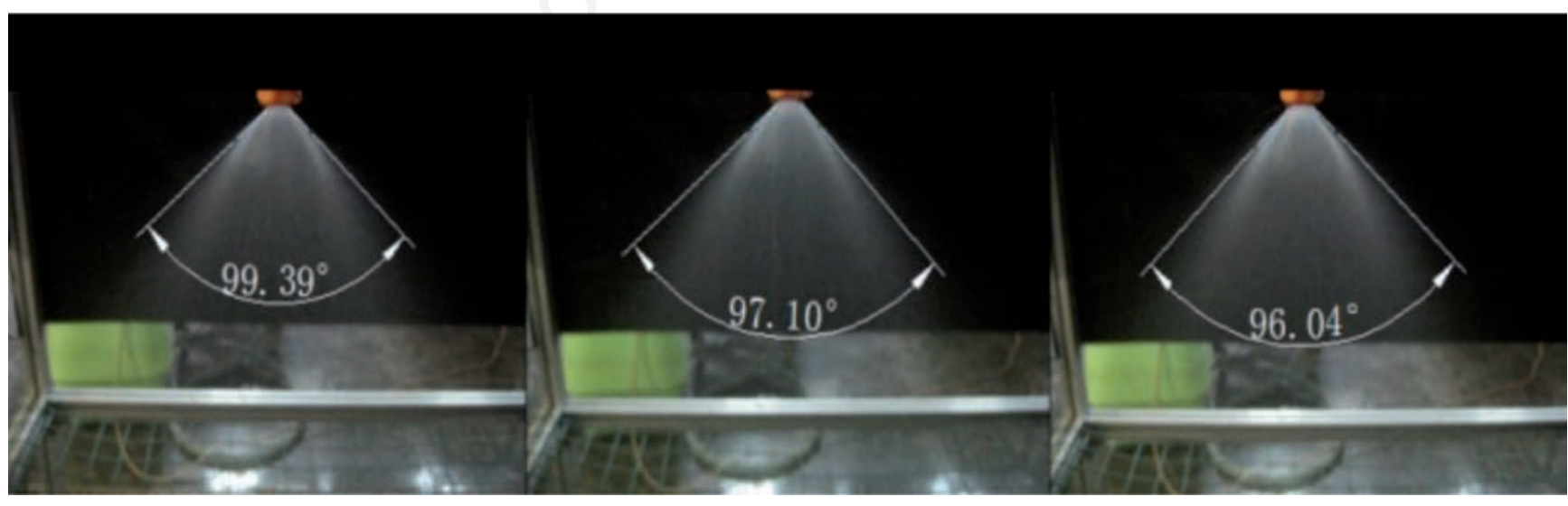

Figure 4. Images of spray angle.

Table 4. Working conditions for measurement of spray distribution.

\begin{tabular}{lcccccc} 
WC & WC1 & WC2 & WC3 & WC4 & WC5 & \\
Frequency/Hz & 6 & 6 & 6 & 6 & 6 & 0 \\
Duty cycle & 0.3 & 0.6 & 0.9 & 0.6 & 0.6 & 0.6 \\
\hline Pressure/MPa & 0.3 & 0.3 & 0.3 & 0.1 & 0.2 & 0.3 \\
\hline
\end{tabular}

WC, working condition. 


\section{Test results of spray angle}

For each working condition, the spray profile was shot thrice and the responding photos shown in Figure 4 were imported to CAD software. The data of the measured spray angle are shown in Table 3 and the average image of the three spray angle photos at each working conditions is shown in Figure 5.

It can be seen in Figure 5 that the frequency and the duty cycle of electromagnetic valves have little influence on spray angles, while spray angle is influenced by spray pressure. On the same working condition, spray angles have no obvious change with the number of nozzles rising. When the pressure was $0.2 \mathrm{Mpa}$, the spray angles stabilised at about $91^{\circ}$, which is regarded as the mean value and the maximum and the minimum deviations from the mean value were separately $0.87^{\circ}$ and $0.03^{\circ}$. When the pressure was $0.3 \mathrm{Mpa}$, the spray angles stabilised at about $98^{\circ}$ (the mean value) and the maximum and the minimum deviations from the mean value were separately $-0.49^{\circ}$ and $0.14^{\circ}$. These results indicate that during the process of variable-rate spray with constant-pressure control, even if there is any change of working conditions on the setting value of spray pressure, frequency, duty cycle, and the number of opening nozzles, the PID closed-loop constant-pressure control can stabilise the spray angle at a certain value.

А) $0.2 \mathrm{Mpa}$

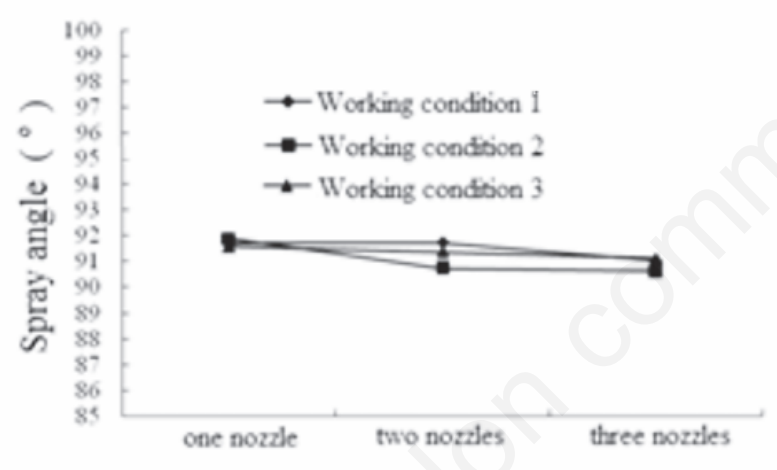

The number of opening nozzles

В) $0.3 \mathrm{Mpa}$

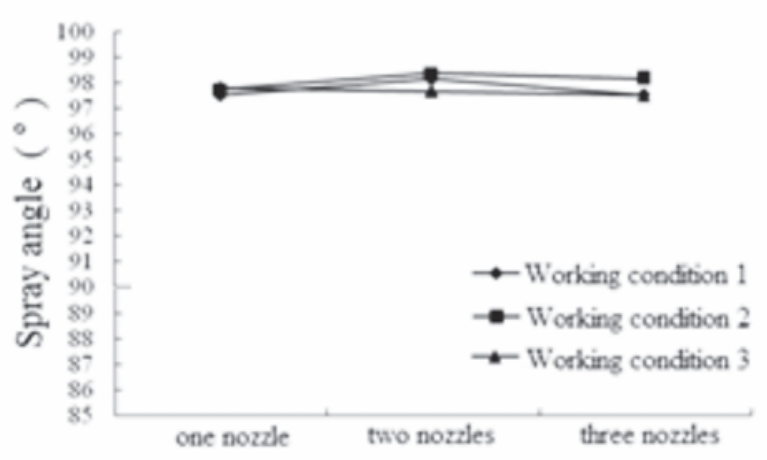

The number of opening nozzles

Figure 5. A-B) Changing tendency of spray angle.

\section{Test result of spray distribution}

The operation of cubic polynomial interpolation was done for experimental data using 2-D (two dimensions) data interpolation function. When the input given pressure of the PID constant-pressure controller was set as $0.3 \mathrm{Mpa}$, the spray distributions on three conditions (WC1, WC2, and WC3 in Table 4) with different duty cycles are shown in Figure 6 . When the frequency and duty cycle were separately set at $6 \mathrm{~Hz}$ and 0.6, the spray distributions on the conditions (WC4, WC5, and WC6 in Table 4) with different spray pressure are shown in Figure 7.

It can be seen from Figure 6 that when the pressure was $0.3 \mathrm{Mpa}$ and with the duty cycle rising, the radial position of the peak value of spray distribution is essentially the same and the peak radius is approximately $250 \mathrm{~mm}$ while the peak value gradually increased, which con-

\section{A) 0.3 duty cycle}

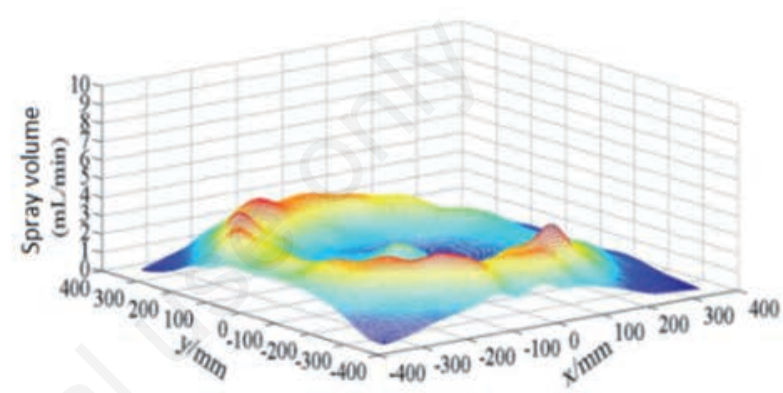

\section{B) 0.6 duty cycle}

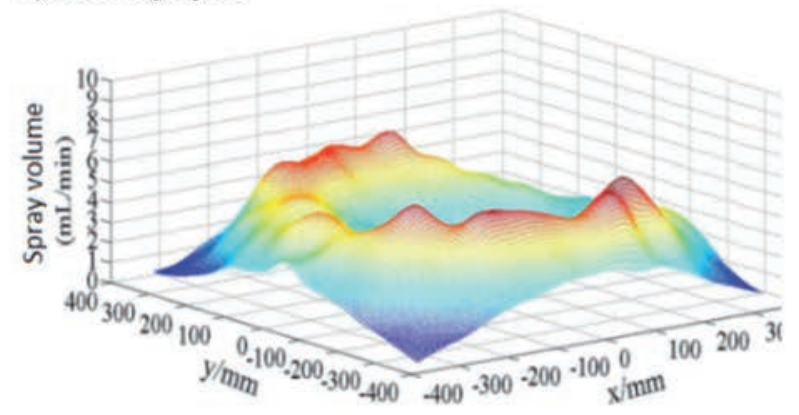

C) 0.9 duty cycle

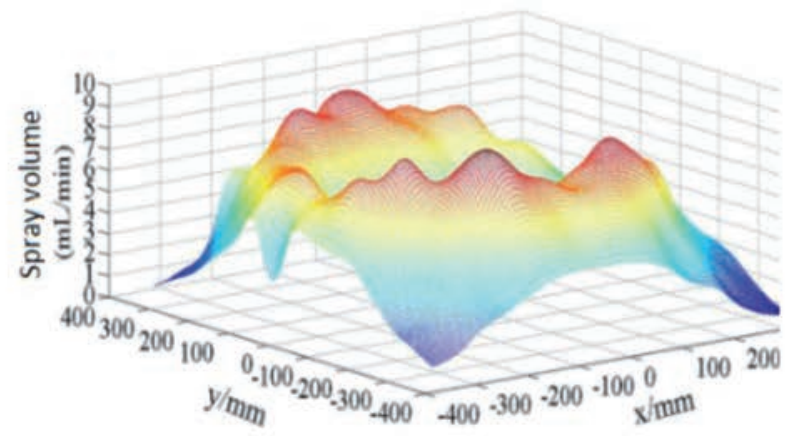

Figure 6. A-C) Spray distribution at the conditions of $0.3 \mathrm{Mpa}$ spray pressure and different duty cycles. 
forms with the ring-shaped spray distribution of hollow-cone nozzles. According to the positions of the peak and the valley values at the center in Figure 7, the differences between the peak and the valley values in the horizontal and vertical directions were respectively calculated under three working conditions with different duty cycles. Under three duty cycles, the differences of the landscape orientation spray distribution between the peak and the valley were respectively $6.3,8.3$, and 11.2 $\mathrm{mL}$, while that of the longitudinal direction were respectively $12.4,26.3$, $41.4 \mathrm{~mL}$. This result shows that the spray distribution in the horizontal direction is more stable than that of the vertical direction.

It is shown in Figure 7 that under condition of the frequency and the duty cycle unchanging and with the pressure rising, the peak value ring of the spray distribution gradually stretch out from the centre, the peak value accordingly decreases, and spray volume increases.

\section{Conclusions}

Compared with the open-loop constant-pressure control using pressure-regulating valves, the closed-loop constant-pressure control using a PID controller with AC chopper and PID feedback regulator can keep the spray pressure stable and avoid the fluctuation of spray pressure caused by the changing flow-rate. Namely, the actual pressure can be stabilised at the set pressure value even though the spray flow-rate was
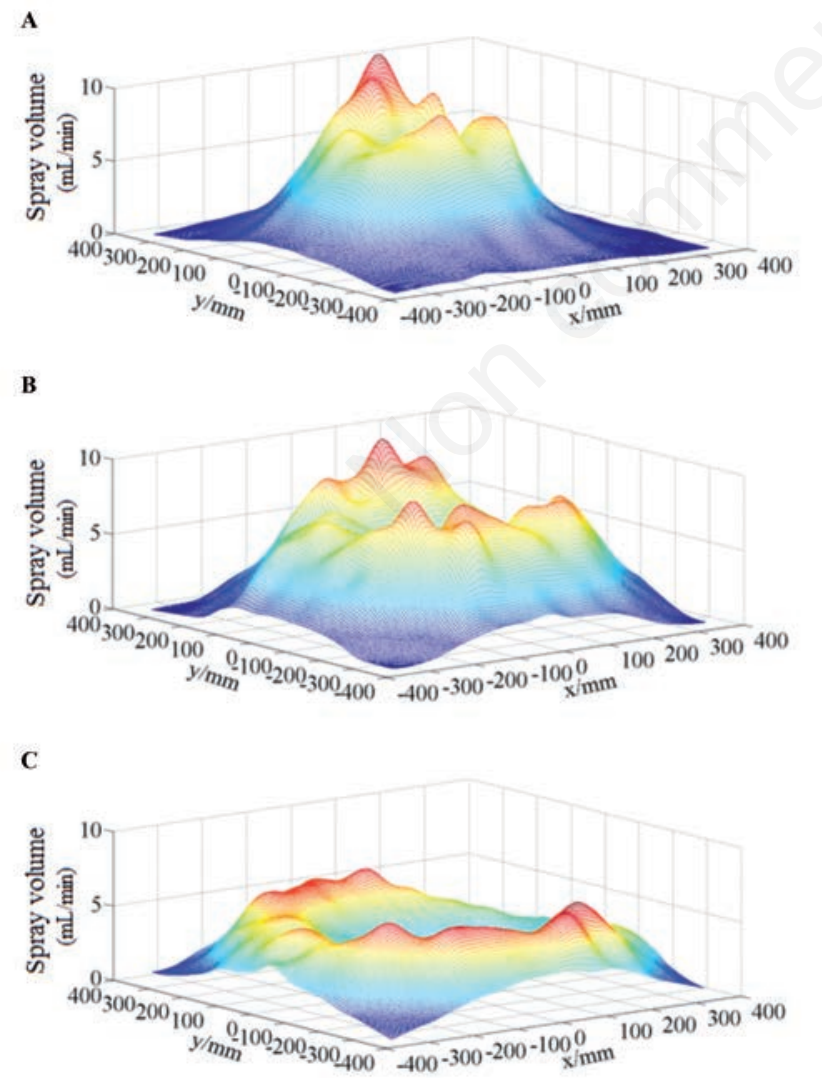

Figure 7. A-C) Spray distribution at the conditions of different spray pressures and same frequency and duty cycle. changed. Therefore, the closed-loop constant-pressure control system would not affected by the changing number of the opening nozzles and ensure a constant spray pressure during the process of variable-rate spray. The control signals of electromagnetic valves, like frequency and duty cycle, and the number of the opening valves had little effects on the spray angle of the hollow-cone nozzle, mode TXVK-18. When the setting pressures were respectively 0.2 and $0.3 \mathrm{Mpa}$, the PID constantpressure controller could stabilise the spray angle of the nozzle at respectively $91^{\circ}$ and $98^{\circ}$, resulting in the maximum and the minimum deviations from the mean value were separately $0.87^{\circ}$ and $0.03^{\circ}$ for 0.2 Mpa setting pressure, $-0.49^{\circ}$ and $0.14^{\circ}$ for 0.3 Mpa setting pressure.

When the setting pressure is $0.3 \mathrm{Mpa}$, the radii of the peak value ring of the spray distribution in the lateral and vertical directions are essentially unchanged with the duty cycle rising, while the peak value gradually increases. The spray distribution in the lateral direction is more stable than that in the vertical direction with the duty cycle changing. When the frequency and the duty cycle were all unchanged, the position of the peak value ring of the spray distribution in the lateral and vertical directions gradually move outside from the centre with the spray pressure rising and accordingly the peak value slowly decreased, while the total spray volume increased. When the spray flow-rate was changed through altering the frequency and the duty cycle, PID constant-pressure controller could ensure the radial position of the peak value of spray distribution in the lateral and vertical directions essentially unchanged.

\section{References}

Alexandre E., Santiago P., Joan R. 2011. Performance of an ultrasonic ranging sensor in apple tree canopies. Sensors 11:2459-77.

Chen S., Yin D., Wei X., Pei W. 2011. Design and simulation of variable weed spraying controller based on adaptive neural fuzzy inference system. J. Drain. Irrig. Mach. Eng. 29:272-6.

Chen Y., Zheng J. 2005. Control system for precision pesticide application based on variable rate technology. T. Chin. Soc. Agric. Eng. 21:68-72.

Deng W., Ding W. 2008. Variable-rate continuous spray equipment based on PWM technology and its spray characteristics. T. Chin. Soc. Agric. Mach. 39:77-80.

Deng W., He X., Zhang L., Zeng A., Song J., Zou J. 2008. Target infrared detection in target spray. Spectrosc. Spect. Anal. 28:2285-9.

Deng W., Zhao C., Ding W., Fu W. 2011. Comparison of spray characteristics for three types of variable spray. Int. Agric. Eng. J. 20:27-37.

Escolà A., Rosell-Polo J.R., Planas S., Gil E., Pomar J., Camp F., Llorens J., Solanelles F. 2013. Variable rate sprayer, Part 1. Orchard prototype: design, implementation and validation. Comput. Electron. Agr. 95:122-35.

Giles D.K., Ben-Salem E. 1992. Spray droplet velocity and energy in intermittent flow from hydraulic nozzles. J. Agric. Eng. Res. 51:101-12.

Giles D.K., Comino J.A. 1990. Droplet size and spray pattern characteristics of an electronic flow controller for spray nozzles. J. Agric. Eng. Res. 47:249-67.

Gui Q., Xu S. 2014. Research on canopy image edge detection algorithm based on fuzzy theory. Acta Agr. Jiangxi 26:109-13.

He X. 2004. Improving severe draggling actuality of plant protection machinery and its application techniques. T. Chin. Soc. Agric. Eng. 20:13-5.

Hu S. 2008. Principles of automatic control. Science Press, Beijing, China.

Huang S., Zhu R., Wang Y., Liu W. 2011. Design and algorithm of constant pressure and variable flow control system of variable pesticide 
application machine. J. Agric. Mech. Res. 2:19-22.

Joan R., Ricardo S., Jordi L., Jaume A., Alexandre E., Manel R., Joan M., Ferran C., Felip G., Francesc S., Tomàs P., Luis V., Santiago P., Emilio G., Jordi P. 2009. A tractor - mounted scanning LIDAR for the non destructive measurement of vegetative volume and surface area of tree - row plantations: a comparison with conventional destructive measurements. Biosyst. Eng. 102:128-34.

Kazerani M. 2003. A direct AC/AC converter based on current-source converter modules. IEEE T. Power Electr. 18:1168-75.

Ling H., Deng W. 2005. The energy saving analysis of the pump's pressure and speed adjustment. J. Xiangtan Normal Uni. Nat. Sci. Ed. 26:54-5.

Ma B., Qi K. 2006. Research on speed regulating method and energy saving analysis in pumps AC motors. Build. Electr. 25:41-7.

Praice M.E.R., Miller P.C.H., Day W. 1996. Control requirements for spatially selective herbicide sprayers. Comput. Electron. Agr. 14:163-77.

Shao L., Dai Z., Cui H., Wei Y., Zhu D., Li B. 2005. Study on a pesticide system spraying with changeable quantity based on fuzzy control. T. Chin. Soc. Agric. Mach. 36:110-2.

Shao L., Dai Z., Wei Y., Ge J., Li B., Zhu D. 2006. The research and simulation of fuzzy controller based on variable applying pesticide of sprayer. J. Syst. Simul. 18:3224-6.

Shen M., Zhang F., Wu X., Liu G., Chen Y. 2013. A method for detecting fruiter crown diameter in variable-rate spray system. J. Graphics 34:115-20.
Sudduth K.A., Borgelt S.C., Hou J. 1995. Performance of a chemical injection sprayer system. Appl. Eng. Agr. 11:343-8.

Wang Z.A., Huang J. 2000. Power electronics. China Machine Press, Beijing, China.

Wei X., Yu D., Bai J., Jiang S. 2013. Static spray deposition distribution characteristics of PWM-based intermittently spraying system. T. Chin. Soc. Agric. Eng. 29:19-24.

Yang S., Yang K. 2009. Basic mechanic engineering control. Huazhong University of Science and Technology Press, Wuhan, China.

Yang X., Yan H., Xu S., Liu Z. 2002. Current situation and development trend of equipment for crop protection. T. Chin. Soc. Agric. Mach. $33: 129-31$

Yu L., Huang J., Zhao Z., Zhang L., Sun D. 2013. Laser measurement and experiment of hilly fruit tree canopy volume. T. Chin. Soc. Agric. Mach. 44:224-8.

Zhai C., Zhao C., Wang X., Liu Y., Ge J., Ma Y., Xue W. 2012. Design and experiment of young tree target detector. T. Chin. Soc. Agric. Eng. 28:18-22.

Zhang L., Zhao Z., Yu L., Zhang Z., Huang J. 2010. Positioning algorithm for ultrasonic scanning of fruit tree canopy and its tests. T. Chin. Soc. Agric. Eng. 26:192-7.

Zhou S. 2013. Research on control strategy in single-phase AC chopper technology. Ind. Contr. Comput. 3:115-6. 